\title{
Ideal selves as identity management strategies
}

\author{
Kitty B. Dumont ${ }^{\mathrm{a}, *}$, Sven Waldzus ${ }^{\mathrm{b}}$ \\ a University of South Africa, Pretoria, South Africa \\ ${ }^{\mathrm{b}}$ Instituto Universitário de Lisboa (ISCTE-IUL), CIS-IUL, Lisboa, Portugal
}

\section{A R T I C L E I N F O}

\section{Article history:}

Received 25 December 2013

Received in revised form 29 July 2014

Accepted 20 November 2014

\section{Keywords:}

Ideals

Social identity

Identity management strategies

\begin{abstract}
A B S T R A C T
This research addresses the relationship between ideal selves and social context from a social identity perspective. Based on Social Identity Theory (Tajfel \& Turner, 1979, 1986) and related research, it is argued that ideal selves stand in a functional relationship with identity management strategies and that, consequently, shared beliefs about relevant intergroup relations influence the preferences for ideal selves. Three studies conducted with black and white adolescent and adult South Africans tested the assumption. The overall results of the studies confirmed that whether ideal selves corresponding to social change, social mobility or social creativity were preferred depended on whether the intergroup relations between black and white South Africans were perceived as secure or insecure.
\end{abstract}

(C) 2014 Elsevier Ltd. All rights reserved.

\section{Introduction}

The idea that individuals can discriminate between who they are and who they would like to be has a long history. In 1898, Estelle M. Darrah asked 1440 school children "What person of whom you have ever heard or read would you most wish to be like?" in her pioneering study on ideals (Darrah, 1898). This study was followed by many others during the 20th century using either the same or very similar questions (an overview is provided by Teigen, Normann, Bjorkheim, \& Helland, 2000). The nature of studying ideals changed with the introduction of the theory of possible selves by Markus and Nurius (1986), in that, ideals as part of possible selves were conceptually linked to the self-concept and therefore theoretically embedded.

The theory of possible selves as a cognitive-motivational theory conceptualises possible selves as cognitive representations (e.g., self-schemata) that derive from representations of the self in the past and the future (Markus \& Nurius, 1986, p. 954). Possible selves appear to have two psychological functions: they motivate behaviour (demonstrated for academic achievement, see Oyserman, Bybee, \& Terry, 2006; career goals, see Strauss, Griffin, \& Parker, 2012; Schnare, MacIntyre, \& Doucette, 2012; and health, see Hooker \& Kaus, 1994) and they provide an evaluative and interpretative frame (Carver \& Scheier, 1998; Hannover, Birkner, \& Poehlmann, 2006; Higgins, 1989). As the traditional approach on ideals (see Teigen et al., 2000), the theory of possible selves assumes that people hold ideal selves, which are conceptualised as assumptions and aspirations about what "we would very much like to become" (Markus \& Nurius, 1986, p. 954).

Both the traditional studies on ideals as well as studies based on the theory of possible selves emphasise the interplay between ideal selves and the social context. In a qualitative review of the traditional studies on ideals from 1889 to 1996, Teigen et al. (2000) identified two general trends for the 20th century: first, the shift from national-historical (e.g., George Washington) towards contemporary ideals (e.g., public media figures such as athletes) and secondly, the shift from

\footnotetext{
* Corresponding author at: P.O. Box 392, UNISA 0003, South Africa. Tel.: +27 124293716

E-mail address: dumonbk@unisa.ac.za (K.B. Dumont).
} 
externalised ideals towards the rejection of external ideals (e.g., increased number of myself answers). Based on the notion that ideals reflect the social and historical context, Teigen et al. (2000) concluded that these shifts mirror changes in societies at large. Likewise, Markus and Nurius (1986) proposed that ideal selves as part of possible selves have the potential to reveal not only the "inventive and constructive nature of the self" but also mirror "the extent to which the self is socially determined and constrained" (p. 954). Although both research traditions acknowledge the importance of the social context, it is, however, surprising that they have not paid much attention to the relationship between social change processes and the individual, yet socially shared construction of the ideal selves. Thus, despite the undeniable link between individual ideal selves and large societal trends, a systematic understanding of the function of ideal selves in the way how people respond and contribute to social change in intergroup relations is still missing. This research aims to contribute to such a systematic understanding.

Given that ideal selves have to our knowledge never been analysed in light of this question, our approach is to a large extent exploratory. However, in order to advance theory development, we propose initial assumptions and hypotheses were they are appropriate. We base our analysis on social identity theory (SIT, Tajfel \& Turner, 1979, 1986) and propose that peoples' ideal selves stand in a functional relationship to their strategies to maintain and develop positive social identities. Moreover, we hypothesise that individuals' preferences for ideal selves are determined by their shared beliefs in sociostructural characteristics of the intergroup relations relevant to them. Three studies that tested this hypothesis within a real intergroup context characterised by radical social changes will be presented.

\subsection{Ideal selves from a SIT perspective}

Ideal selves are part of the self-concept that defines the personal self. The self-concept of individuals, however, does not only consist of their personal selves but also of their social selves (Brewer \& Gardner, 1996). People belong to different groups (e.g., occupational group) and social categories (e.g., gender, race, etc.); and this belonging as well as the associated importance of these groups and social categories determines their social selves and identities. This leads to the question of whether ideal selves as cognitive representations are limited to ideal personal selves or whether they extend also to social selves. In a first approach, Cinnirella (1998) elaborated this question theoretically from the perspective of social identity theory (Tajfel \& Turner, 1979, 1986) and introduced the notion of possible social identities. He defined possible social identities as individual and shared cognitions about "possible past group memberships, possible future memberships, and perceptions of the possible past and future for current group memberships" (Cinnirella, 1998, p. 227). Furthermore, he proposed that cognitive alternatives of intergroup relations as conceptualised within social identity theory should be expanded to incorporate possible social identities. Likewise, the present research focuses on social aspects of ideal selves. However, it diverges from Cinnirella's (1998) idea. Rather than proposing to extend social identity theory by considering possible social identities, we propose to extend our understanding of ideal personal selves and their interrelatedness to the social context from the perspective of social identity theory. Thus our focus is less on possible/ideal group memberships as such, but rather on the function of ideal personal selves in intergroup relations involved in social change.

Social identity theory (SIT, Tajfel \& Turner, 1979, 1986) states that social identity consists of that part of the self-concept that is based on the knowledge of being a member of one or more social groups, together with the evaluation and emotional significance of that group membership. One of the basic assumptions of SIT is that people strive for positive social identity which can be achieved by positive distinctiveness as a result of comparison of the ingroup with a relevant comparison group on a relevant comparison dimension. Given the condition that positive distinctiveness cannot be reached or that it is perceived as threatened, social identity theory predicts that people engage in identity management strategies to gain or maintain positive social identity. Tajfel and Turner $(1979,1986)$ distinguished three identity management strategies: individual mobility (i.e., the individual's position is changed whilst the status relations between the comparison groups remain unchanged); creativity strategies (i.e., comparison references are changed in one or the other way so that negative comparison results become less important) and social competition (i.e., to seek social change). Based on self-categorisation theory (Turner, Hogg, Oakes, Reicher, \& Wetherell, 1987) an additional strategy was introduced by Blanz, Mummendey, Mielke, and Klink (1998) which is called individualisation. The notion of individualisation essentially describes the shift from social to personal self-categorisation, i.e., people attribute more importance to their personal than to their social identity. Similar to social mobility, this strategy allows people to escape from their negative social identity while the status relation between ingroup and outgroup and its evaluation remains unchanged.

We argue that identity management strategies correspond with ideal selves. The reason is that the various types of ideal selves differ in their instrumentality for approaching positive social identity depending on the nature of the identity management strategy that is at stake. For instance, in social competition it might not be very useful to identify with outgroup prototypes or ideals promoting individualisation because those might be seen as undermining ingroup cohesion and solidarity. Instead, it might be much more appropriate to identify with real/imagined persons that are perceived to be motivated and able to challenge current status relations between ingroup and outgroup. Such ideal selves representing social change are usually revolutionaries, politicians, or religious leaders. In contrast, such revolutionary ideals might not be instrumental for pursuing social mobility. The latter requires ideals that are prototypical for the outgroup thereby allowing approaching this group and eventually becoming one of them. The strategy of individualisation conforms with a real/imagined person that allows the individual to shift from social to personal self-categorisation. Ideal selves are instrumental for such a shift if they symbolise a uniqueness (e.g., an ideal personifying "oneself" or family members) that is rather unlikely to be affected 
Table 1

SIT and corresponding ideal selves.

\begin{tabular}{|c|c|c|c|}
\hline $\begin{array}{l}\text { Shared belief of } \\
\text { intergroup relations }\end{array}$ & $\begin{array}{l}\text { Intergroup comparison } \\
\text { outcome }\end{array}$ & $\begin{array}{l}\text { Social identity } \\
\text { management strategies }\end{array}$ & Corresponding ideal selves \\
\hline $\begin{array}{l}\text { Insecure (instable } \\
\text { and/or illegitimate) }\end{array}$ & $\begin{array}{l}\text { Dominant/non- } \\
\text { dominant }\end{array}$ & Social competition & $\begin{array}{l}\text { Real/imagined person that challenges or reinforces current status } \\
\text { relations (e.g., revolutionaries, politicians, religious leaders, etc.) }\end{array}$ \\
\hline \multirow{5}{*}{$\begin{array}{l}\text { Secure (stable and/or } \\
\text { legitimate) }\end{array}$} & \multirow[t]{3}{*}{ Non-dominant } & Social mobility & Real/imagined person that represents a prototype of the outgroup \\
\hline & & Individualisation & $\begin{array}{l}\text { Real/imagined person that represents symbolises a uniqueness } \\
\text { (e.g., "myself" answers and family members) }\end{array}$ \\
\hline & & Social creativity & $\begin{array}{l}\text { Real/imagined person that represents a prototype of the ingroup } \\
\text { (e.g., historical and contemporary public figures from ingroup) }\end{array}$ \\
\hline & \multirow[t]{2}{*}{ Dominant } & Social creativity & Popular figures irrespective of ingroup or outgroup \\
\hline & & Individualisation & $\begin{array}{l}\text { Real/imagined person that represents symbolises a uniqueness } \\
\text { (e.g., "myself" answers and family members) }\end{array}$ \\
\hline
\end{tabular}

by any intergroup evaluation. Lastly, strategies to lessen the importance of negative comparison outcomes (social creativity) correspond with ideal selves representing a prototype of the ingroup. The reason is that such a kind of ideal self allows individuals to refrain from negative intergroup comparison outcomes by focussing on standards and norms that are determined by ingroup values instead. Ideal selves that exemplify these standards are popular figures such as pop stars, sport stars, glamorous figures as well as personal acquaintances such as teachers and friends (provided they are members of the ingroup).

It is important to note that identity management strategies are not only characteristic for non-dominant groups but also for dominant groups if their positive social identity is threatened. Such a threat is likely if the non-dominant group is perceived to challenge the status quo or if perceived injustice of intergroup differences leads to a conflict of values "of such intensity that it destroys the positive contribution to social identity that the group provides” (Tajfel, 1981, p. 280).

Numerous experimental (e.g., for an overview see Ellemers, 2002) and field studies (e.g., Dumont \& van Lill, 2009; Ellemers \& Bos, 1998; Kessler \& Mummendey, 2002; Mummendey, Kessler, Klink, \& Mielke, 1999; Mummendey, Klink, Mielke, Wenzel, \& Blanz, 1999; Niens, Cairns, Finchilescu, Forster, \& Tredoux, 2003, Campbell, 1995a, 1995b) have demonstrated for both dominant and non-dominant groups that identity management strategies are determined by the shared beliefs about intergroup status relations as either insecure or secure, i.e., whether cognitive alternatives of the intergroup relations are available and/or conceivable or not (Tajfel \& Turner, 1979, pp. 44-45). The belief of insecure intergroup relations assumes unstable and/or illegitimate status differences (i.e., availability of cognitive alternatives); whereas the belief of secure intergroup relations assumes stable and legitimate status differences (i.e., no cognitive alternatives). As the constellations of these shared belief systems are linked to the different identity management strategies they should accordingly influence the preference for ideal selves. Before considering the specificities of any particular intergroup context it is necessary the outline the theoretical predictions regarding these preferences for non-dominant and dominant groups (see Table 1).

More precisely and in accordance with social identity theory we postulate: first, members of non-dominant groups that share the belief of insecure intergroup relations (instable and/or illegitimate status differences) are likely to prefer ideal selves personifying the promotion of social change (e.g., political figures). Secondly, members of non-dominant groups that share the belief of secure intergroup relations (stable and legitimate status differences) are likely to prefer ideal selves that either personify change in the individual's position, whilst the intergroup relations remain unchanged (social mobility and individualisation); or personify an alternative comparison references (creativity strategies). The latter is more likely when the former strategy is objectively or subjectively impossible (e.g., when group boundaries are impermeable, see Ellemers, Van Knippenberg, De Vries, \& Wilke, 1988; or when individuals are highly committed to their group, see Ellemers, Spears, \& Doojse, 1997).

Thirdly, members of dominant groups that share the belief of insecure intergroup relations (instable and/or illegitimate status differences) are likely to prefer ideal selves personifying the prevention of social change or the re-establishment of legitimate dominance (Haslam, 2001, p. 39; Tajfel, 1981). Both, prevention of social change or re-establishment of legitimate dominance are most likely to be achieved by ideals such as political figures and/or religious leaders. Fourthly, we would like to note that we have no particular predictions for functional preferences in dominant groups in stable and legitimate status relations (i.e., secure intergroup relations), because they should not feel any need for engaging in identity management strategies. From the available literature it can be derived that members of such groups can afford to be rather unconcerned about the intergroup context, interact more on the interpersonal level with their own kind (Simon, Aufderheide, \& Kampmeier, 2001) and define themselves more as individuals and by interpersonal rather than intergroup comparisons. Even though their choices of ideal selves would not primarily be motivated by social identity management as in the other cases, one can expect a certain preference for popular figures (irrespective of ingroup or outgroup) or unique ideal selves, that is, a pattern that usually corresponds to social creativity or individualisation.

In the following, we report three studies that tested the proposed functional relationships between ideal selves and social identity management strategies. All three studies were conducted in South Africa, where a radical social change process has been taking place in order to overcome the legacy of apartheid (Habib \& Bentley, 2008). This dynamic context of social change requires a careful exploration of the actual perceived status positions in order to apply the theoretical framework as outlined above. 


\section{Study 1}

The aim of Study 1 was to investigate the function of ideal selves, as outlined in the above-mentioned hypotheses, in intergroup relations involved in social change. As mentioned before, South Africa is undergoing one of the most radical social change processes; which, for historical reasons, manifests itself particularly in the intergroup relations between black and white South Africans. Consequently, Study 1 was conducted with black and white adolescent South Africans. For the sake of comparability with previous research, ideal selves were assessed by using the traditional approach (e.g., What person of whom you have ever heard or read would you most wish to be like?).

\subsection{Method}

\subsubsection{Participants}

The participants were 170 pupils from two high schools located in East London, South Africa. In total, 68 categorised themselves as black while 102 considered themselves white South Africans. The black adolescents were slightly older $(M=15.35)$ than the white adolescents $(M=14.97, t(168)=2.56, p<.05)$. The gender distribution was relatively well balanced in these two samples with 33 females and 35 males in the black sample, and 63 females and 39 males in the white sample. Ethical clearance was obtained from the University of Fort Hare, the local university in this province, and permission for this study was given by the headmasters of the respective schools.

\subsubsection{Procedures and measures}

Using questionnaires the participants were first asked What person of whom you have ever heard or read would you most wish to be like? On a separate page the intergroup status relations were assessed and finally the participants were asked for their socio-demographic data. The collected ideal selves were assigned by two independent raters (a black and a white South African) to an adapted and extended version of Teigen et al.'s (2000) classification system: myself, family (individualisation), personal acquaintances, popular figures (social creativity), religious and political figures (social competition), and ideals from the outgroup (social mobility). The raters classified the ideal selves in the first step according to the classification system. In a second step they classified the ideal selves as ingroup or outgroup members. As we expected most ambiguity to occur in relation to the ingroup and outgroup classification of personal acquaintances it was decided to apply a rather conservative approach. Only those ideals were included if additional information was provided which allowed ingroup and outgroup classification. For instance, if a black participant named his "friend Kopano" (a common name among black but not among white South Africans) as ideal self, it was classified as social creativity in the form of personal acquaintances. If a white participant named his "friend Kopano" as ideal self, it was classified as social mobility. If a participant named his/her "friend" as ideal self, it was not included at all.

A Kappa of $.86(p<.001)$ was achieved for assigning the ideal selves to the extended version of Teigen et al.'s (2000) classification system and a Kappa of 1 was achieved for categorising the ideals as either ingroup (e.g., white people for white participants) or outgroup (e.g., black people for white participants) representatives. All remaining ambiguous cases were discussed by the raters until agreement was reached.

Participants' beliefs about the status relations between black and white South Africans were assessed by using the intergroup perception ladder representing an adaptation of Cantril's Self-Anchoring Striving Scale (Finchilescu \& de la Rey, 1991). Participants were presented with a drawing of a ladder with 12 steps (labelled from 0 to 11 ) and asked to imagine that this ladder represented economic status in South Africa. The top step represented the best economic status one could imagine while the bottom step was the worst. The task of the participants was to indicate their opinion about which step their ingroup and the respective comparison group stood on 25 years ago, in the present, in 15 years' time and ideally. The comparison of past, current and future status positions informed about perceived stability versus instability of the intergroup status relations, whereas the comparison with the ideal status position allowed for inferences of perceived legitimacy of the different status positions in the present, past and future.

\subsection{Results}

\subsubsection{Preliminary analysis}

First, we explored how the white and black participants judged the status relations between black and white South Africans (see Figs. 1 and 2). Black participants perceived that economic status differences were large in the past, $t(65)=-8.31$, $p<.001$, much smaller, but still significant, in the present, $t(65)=-2.18, p<.05$, and absent in the future, $t(65)=0.17, p=.86$. According to these results, black participants experienced their ingroup as non-dominant for the past and present even though they would assume equal status relations in the future. However, black participants wished that black and white South Africans would ideally hold unequal economic status, $t(65)=3.5, p<.01$, in that the ingroup should represent the dominant group. White participants, on the other hand, reported that economic status differences were significant in the past, $t(89)=17.31, p<.001$, present, $t(89)=-2.72, p<.01$, and future, $t(89)=-6.30, p<.001$, in that white relative to black South Africans had had a dominant status in the past, while the status relations in the present and future would be reversed. Ideally white participants wanted black and white South Africans to have a equal economic status, $t(89)=-1.21, p=.23$. 


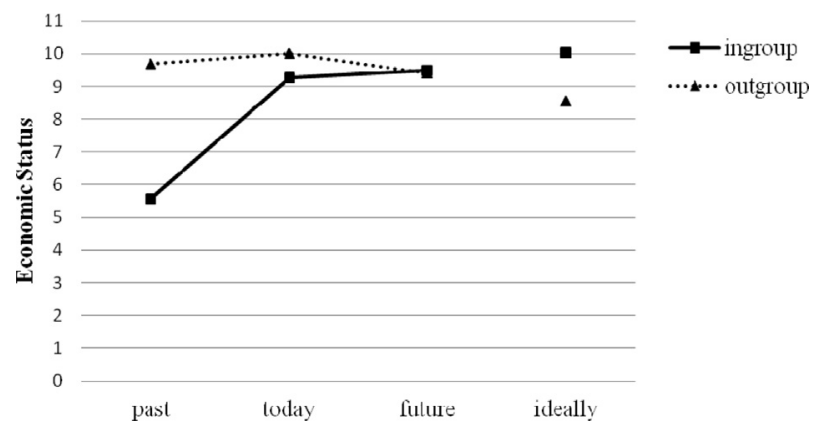

Fig. 1. Black participants' perceptions of economic status relations between black and white South Africans, Study 1 .

White South Africans are perceived as losing their dominant position while black South Africans are perceived as gaining economic dominance. These perceptions reflect the intended trends of the social change process in South Africa, which has meanwhile been institutionalised in that not only affirmative action in education, employment and sport is legally claimed, but also programmes such as black economic empowerment (Habib \& Bentley, 2008). One interesting aspect of such institutionalised social change, which is not yet considered in social identity theory, is that non-dominant groups who expect to profit from such institutionalised change processes perceive actually the intergroup situation as secure, not because social change is unlikely but because it is secure as it is protected by powerful institutions. One could argue that those alternative comparison outcomes projected into the future allow members of such groups to frame social reality in terms of being actually in an advantaged position which leave them with little necessity to actively engage in social competition. It might also leave them with little reason to distance themselves from their ingroup by individualisation or social mobility since being a member of such an advantaged group is highly attractive. We therefore predicted that black participants are likely to report ideal selves corresponding with those that are expected for dominant groups in secure intergroup relations. However, there should be a preference for popular ingroup figures (social creativity) rather than unique ideal selves (individualisation) given that their group membership is a necessary condition for their future status gain (H1).

White participants perceive their ingroup as non-dominant economically as well as the intergroup relations between black and white South Africans as secure. However, different to their black counterparts, their perceptions of secure intergroup relations refer to social change as unlikely since white South Africans are assumed to maintain their non-dominant position in the future. It was therefore predicted that white participants are likely to report ideal selves that either personify change in the individual's position (social mobility and individualisation), or a prototype of the ingroup (social creativity) (H2).

\subsubsection{Hypothesis testing}

Table 2 summarises the observed and expected frequency of ideal selves. The results show that $\mathrm{H} 1$ and $\mathrm{H} 2$ were supported. The overall Pearson Chi-Square Test, $\chi^{2}(5)=39.06, p<.001$, as well as the follow-up tests of multiple $2 \times 2$ relationships indicate that black participants named ingroup celebrities such as Patrice Motsepe, Kabelo, and Zola more frequently, $\chi^{2}(1)=11.32, p<.001$; whereas white participants named their mothers and fathers, $\chi^{2}(1)=20.92, p<.001$, and themselves, $\chi^{2}(1)=8.61, p<.01$, significantly more often. The latter result suggests that white adolescents tended to prefer ideal selves that allowed them to shift from social to personal self-categorisation (i.e., individualisation). The results further supported our reasoning that groups such as the black participants who perceive social change as secure are left with little necessity to actively engage in social competition in that ideal selves corresponding with social change (e.g., political figures) were rather rare.

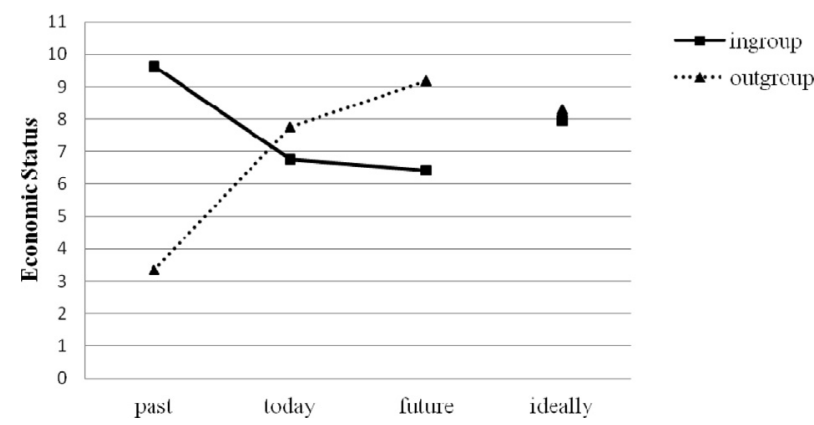

Fig. 2. White participants' perceptions of economic status relations between black and white South Africans, Study 1. 
Table 2

Frequencies and expected frequencies of possible selves, Study 1 .

\begin{tabular}{lcc}
\hline Categorised possible selves & Sample & White \\
\cline { 2 - 3 } & $\begin{array}{l}\text { Black } \\
(n=68)\end{array}$ & $102)$ \\
\hline Social mobility & $10(6.8)$ & $7(10.2)$ \\
$\quad$ Ideals from outgroup & $0(4.8)$ & $12(7.2)$ \\
Individualisation & $8(21.6)$ & $46(32.4)$ \\
$\quad$ Myself & $7(4.8)$ & $5(7.2)$ \\
$\quad$ Family & $39(28.4)$ & $32(42.6)$ \\
Social creativity & $4(1.6)$ & $0(2.4)$ \\
$\quad$ Personal acquaintances & 0 & 0 \\
$\quad$ Popular figures & & \\
Competition & & \\
$\quad$ Political figures & & \\
\hline
\end{tabular}

Note. Expected frequencies are reported in brackets.

\subsection{Discussion}

The results were largely in line with our predictions in that black participants reported prototypical ingroup representatives as ideal selves (i.e., social creativity in the form of popular figures) more frequently; while white adolescent participants reported more frequently ideal selves personifying uniqueness (e.g., individualisation in the form of "myself" answers and family).

We argued that white participants perceive the economic intergroup relations between white and black South Africans as disadvantaged and secure. Yet, if we take the results for the ideal intergroup relations into consideration one could as well argue that these differences are perceived as illegitimate. Following the reasoning of Tajfel (1981, p. 250) that "[...] there is little doubt that an unstable system of social divisions between groups is more likely to be perceived as illegitimate than a stable one; and that conversely a system perceived as illegitimate will contain the seeds of instability", white participants should have named ideal selves representing social change. However, none of our participants did. Does this result mean that the functional relation of ideal selves in intergroup relations does not follow the logic of social identity theory? We would find such a conclusion premature. We would rather argue that seeing status differences as "illegitimate will contain the seeds of instability" only if changes in the intergroup relations are perceived as achievable in the future. The latter might depend on the perceptions of the social power at stake (e.g., Simon \& Oakes, 2006; Turner, 2005).

We subjected our alternative reasoning to the test and conducted a second study which included two additional measures that aimed to capture more precisely the perceived achievability of social change. First, we assessed not only the perceptions of economic status relations between black and white South Africans but also political status relations. Secondly, we followed de la Sablonniere, Taylor, Perozzo, and Sadykova (2009), who demonstrated that group comparisons at several future points increase the understanding of peoples' anticipations of changing conditions. Consequently, two future points were distinguished in Study 2: in 15 years' time and in 50 years' time.

\section{Study 2}

The aim of the second study was not only to replicate the findings of Study 1 but also to examine the plausibility of the alternative hypothesis discussed in Study 1 by gaining a clearer understanding of the beliefs regarding the security or insecurity of the intergroup status relations. We reasoned that, different from our assumptions, the intergroup situation might be seen as insecure if perceptions of political status, particularly in the future, would imply power constellations that could put at risk the future gain in relative status for black South Africans and thereby give hope to white South Africans to overcome their perceived non-dominant status in the long run. To test whether this was actually the case, two additional measures were included, which assessed more distant status predictions as well as judgments on political status.

\subsection{Method}

\subsubsection{Participants}

In total 206 pupils from two high schools located in East London (different from Study 1) participated in Study 2. Onehundred and eight classified themselves as black South Africans and 98 as white. On average the participants were 15.32 years old (ranging from 13 to 25). The two samples neither differed in age (black: 15.56, whites: 15.11) nor in the gender ratio. In total 121 were female (blacks: 65 , whites: 56 ) and 84 were male (blacks: 42, whites: 42). As in Study 1, ethical clearance was obtained from the University of Fort Hare and permission for this study was given by the headmasters of the respective schools. 


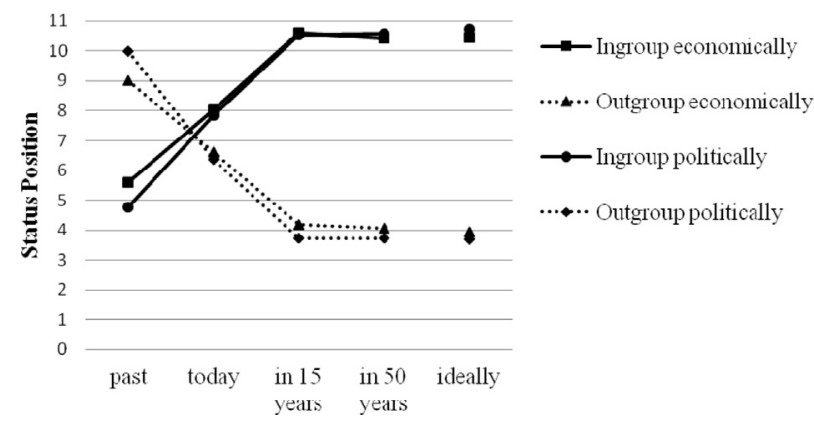

Fig. 3. Black participants' perceptions of economic and political status relations between black and white South Africans, Study 2 .

\subsubsection{Procedure and measures}

The procedure of Study 2 was identical to that applied in Study 1 except for two changes: first, political status relations between white and black South Africans were assessed using a second intergroup perception ladder. The top step (11) represents the most political power one could imagine while the bottom step (0) represents the least political power. Secondly, future status relations were specified by distinguishing between in 15 years' time and in 50 years' time.

Ideal selves were assigned to the classification system as used in Study 1. The interrater reliability was Kappa $=.81$ $(p<.001)$. Ideal selves were also classified as either ingroup (e.g., white people) or outgroup (e.g., black people) representatives using the procedure as in Study 1, Kappa $=1$.

\subsection{Results}

\subsubsection{Preliminary analysis}

The preliminary analysis explored the participants' perceptions of the relations between black and white South Africans with regard to both economic and political status. Fig. 3 summarises the perceptions of black participants. They perceived economic and political status differences between black and white South Africans as significant for the past, $t_{\text {econ }}(101)=-3.15, p<.001, t_{\text {polit }}(104)=-4.92, p<.001$, the present, $t_{\text {econ }}(110)=1.90, p<.05, t_{\text {polit }}(105)=1.78, p<.05$, in 15 years' time, $t_{\text {econ }}(104)=6.64, p<.001, t_{\text {polit }}(99)=6.84, p<.001$, in 50 years' time, $t_{\text {econ }}(104)=6.46, p<.001, t_{\text {polit }}(105)=6.83$, $p<.001$, and ideally, $t_{\text {econ }}(102)=6.54, p<.001, t_{\text {polit }}(101)=6.93, p<.001$. The ingroup was perceived as non-dominant economically and politically for the past but already on its way to being dominant. Superior status economically and politically is anticipated for the future and as the ideal.

White adolescent participants perceived economic and political status differences between black and white South Africans as significant for the past, $t_{\text {econ }}(91)=5.69, p<.001, t_{\text {polit }}(94)=6.07, p<.001$, the present, $t_{\text {econ }}(92)=-2.47, p<.001$, $t_{\text {polit }}(94)=-5.37, p<.001$, in 15 years' time, $t_{\text {econ }}(92)=-3.33, p<.001, t_{\text {polit }}(93)=-5.32, p<.001$, and in 50 years' time, $t_{\text {econ }}(92)=-3.92, p<.001, t_{\text {polit }}(93)=-4.48, p<.001$, in that, the ingroup is perceived as dominant economically and politically in the past but as non-dominant in the present and future (Fig. 4). Ideally, black South Africans are perceived to have more political power, $t_{\text {polit }}(92)=-0.95, p<.05$, but to share equal economic status with white South Africans, $t_{\text {econ }}(91)=-0.41$, $p>.05$.

The outlined average judgments of economic and political status relations between black and white South Africans replicate the findings of Study 1 in that black and white participants perceived secure status relations. Black participants perceive the intergroup relations as secure in that social change is secure due to the political power constellation. Their ingroup is already having and further gaining both economic and political status superiority, which would be maintained

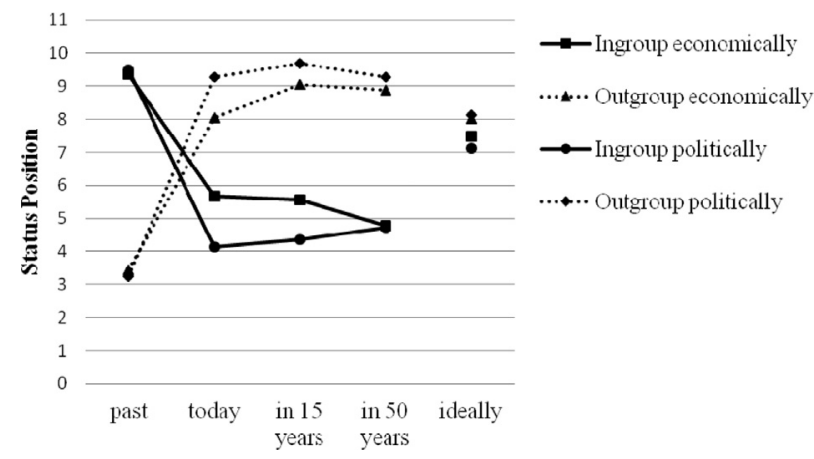

Fig. 4. White participants' perceptions of economic and political status relations between black and white South Africans, Study 2. 
Table 3

Frequencies and expected frequencies of ideals, Study 2.

\begin{tabular}{lll}
\hline Categorised possible selves & Sample & White \\
\cline { 2 - 3 } & $\begin{array}{l}\text { Black } \\
(n=89)\end{array}$ & $89)$ \\
\hline Social mobility & $11(12.3)$ & $12(10.7)$ \\
$\quad$ Ideals from outgroup & $0(5.7)$ & $11(5.3)$ \\
Individualisation & $8(23)$ & $35(20)$ \\
$\quad$ Myself & $18(11.3)$ & $3(9.7)$ \\
$\quad$ Family & $67(55.2)$ & $36(39.8)$ \\
Social creativity & $8(4.3)$ & $0(3.7)$ \\
$\quad \begin{array}{l}\text { Personal acquaintances } \\
\text { Popular figures }\end{array}$ & 0 & 0 \\
Social competition & & \\
$\quad$ Political figures & & \\
$\quad$ Religious figures & &
\end{tabular}

Note. Expected frequencies are reported in brackets.

in the distant future. This anticipated trend is in line with the ideally perceived intergroup relations, characterised by ingroup economical and political superiority. Consequently and for the same reasons as in Study 1, we predicted that black participants are likely to report popular ingroup figures as ideal selves (social creativity) (H1).

White participants' perceptions of secure intergroup relations, in contrast, indicate that their ingroup had lost both economic and political status, which would not be regained in the near or distant future. They recognised that the political power constellation would not allow for reversing the trend, not even in the future (i.e., little hope for social change in the sense of regaining relative status). Furthermore, the expressed ideal political status relations between black and white South Africans implies superiority of the outgroup and suggests that white participants do not only perceive changes in the intergroup relations as very unlikely in the future, but also recognise some legitimacy of their inferior political status position. Thus, there was little plausibility for the alternative hypothesis as discussed in Study 1 (i.e., perception of insecure status relations by white participants). Like in Study 1 we therefore predicted that white participants are likely to prefer ideal selves that personify either change in the individual's position (social mobility and individualisation), or a prototype of the ingroup (social creativity).

\subsubsection{Hypothesis testing}

The results as summarised in Table 3 basically replicate the findings of Study 1. The overall Pearson Chi-Square Test, $\chi^{2}(5)=55.25, p<.001$, was significant and the follow-up tests of multiple $2 \times 2$ relationships revealed that black participants named personal acquaintances, $\chi^{2}(1)=11.37, p<.001$ and popular figures, $\chi^{2}(1)=10.60, p<.01$, such as Princess Magogo, Patrick Motsepe, and Oprah more frequently; whereas white participants named their mothers and fathers, $\chi^{2}(1)=26.18$, $p<.001$, and myself answers, $\chi^{2}(1)=13.31, p<.001$, more frequently (H2). Like in Study 1 , ideals that could represent engagement in social change were rather rare.

\subsection{Discussion}

The results of Study 2 supported our hypotheses. Consistent with Study 1, it was found that black participants mostly named ideal selves personifying ingroup prototypes (i.e., social creativity); whereas white participants, apart from ingroup prototypes (i.e., social creativity) named ideal selves personifying the shift from social to personal self-categorisation (i.e., individualisation in the form of "myself" answer and family).

In Study 1 and Study 2 both black and white participants perceived the intergroup relations between white and black South Africans as secure yet with different expectations. However, if our assumption that ideal selves stand in a functional relationship with social identity management strategies was to be correct it would be crucial to demonstrate that insecure status relations increase the likelihood of ideal selves that promote social change. Given the contemporary history of South Africa's liberation movement one could assume that insecure status relations between black and white South Africans must have been perceived by the majority of black South Africans since the mid-1970s until the apartheid system eventually was overcome. Due to the fact that no data on ideal selves was available from this time, we decided to ask South African adults about their ideal selves when they were adolescents.

\section{Study 3}

In Study 3 we tested the hypothesis that insecure status relations should increase the likelihood for ideal selves personifying social change. 
Table 4

Frequencies and expected frequencies of ideals, Study 3.

\begin{tabular}{|c|c|c|}
\hline \multirow[t]{2}{*}{ Categorised ideals } & \multicolumn{2}{|l|}{ Sample } \\
\hline & $\begin{array}{l}\text { Black } \\
(n=60)\end{array}$ & $\begin{array}{l}\text { White } \\
(n=45)\end{array}$ \\
\hline \multicolumn{3}{|l|}{ Social mobility } \\
\hline Ideals from outgroup & $0(1.1)$ & $2(0.9)$ \\
\hline \multicolumn{3}{|l|}{ Individualisation } \\
\hline Myself & $1(2.3)$ & $3(1.7)$ \\
\hline Family & $13(13.7)$ & $10(9.9)$ \\
\hline \multicolumn{3}{|l|}{ Social creativity } \\
\hline Personal acquaintances & $11(9.1)$ & $5(6.9)$ \\
\hline Popular figures & $4(17.1)$ & $25(12.4)$ \\
\hline \multicolumn{3}{|l|}{ Social competition } \\
\hline Political figures & $28(16)$ & $0(12)$ \\
\hline Religious figures & $3(1.7)$ & $0(1.3)$ \\
\hline
\end{tabular}

Note. Expected frequencies are reported in brackets.

\subsection{Method}

\subsubsection{Participants}

In total, 105 adult South Africans participated in Study 3. These adults were approached on streets, in shopping malls, and at hairdressers located in the East London area (Eastern Cape). Sixty participants categorised themselves as black South Africans, and 45 as white South Africans. The average age of the participants was 42.63 (ranging from 33 to 56 years). No group differences were found with respect to age (blacks: $M=42.32$; whites: $M=43.04$ ). The majority of the black sample were male $(44$, female $=16)$ while the majority of the white sample were female $(36$, male $=9)$.

\subsubsection{Procedures and measures}

The questionnaires for the adults were identical to the previous two studies except with regard to the tense used in the question asking about ideals: What person of whom you heard or read wished you most to be like when you were a teenager? Ideal selves were assigned to the classification system as used in the previous studies. The interrater reliability was Kappa $=.81(p<.001)$. The classification of ideal selves as either ingroup (e.g., white people) or outgroup (e.g., black people) representatives revealed a Kappa $=1$.

The participants' beliefs about the status relations between black and white South Africans in the past were assessed similar to Study 1 and 2. The participants were asked to indicate about which step their ingroup and the respective comparison group stood on 25 years ago (i.e., during apartheid).

\subsection{Results}

\subsubsection{Preliminary analysis}

First, we explored how white and black adult participants judged the status relations between black and white South Africans during apartheid. Black adult participants perceived the status differences as significant, $\left(M_{\text {white }}=10.55, \mathrm{SD}=1.41\right.$; $\left.M_{\text {black }}=1.78, \mathrm{SD}=1.82\right), t(59)=30.91, p<.001$, in that their ingroup was non-dominant; whereas white adult participants perceived their ingroup as dominant, $\left(M_{\text {white }}=10.06, \mathrm{SD}=1.18 ; M_{\text {black }}=2.16, \mathrm{SD}=1.79\right), t(59)=30.91, p<.001, t(42)=22.27$, $p<.001$.

By using the outlined average judgments of the status relations between black and white South Africans during apartheid, we concluded for the white adult participants that since they perceive their group as dominant in the past and, most importantly, since the apartheid system ensured the dominant status position for white South Africans, the majority perceived the status relations between black and white South Africans as secure at the time they were adolescents. We therefore predicted (H1) that white adult participants would more likely report retrospectively ideal selves who were prototypical representatives of the ingroup (e.g., popular figures) or unique ideal selves (e.g., individualisation). In contrast, black adult participants judged their ingroup as non-dominant in the past. Given that the anti-apartheid struggle particularly after the student uprisings in 1976 became a strong mass movement among young black South Africans, the majority of our adult participants were assumed to have perceived the status relations as insecure at the time they were adolescents. Consequently, we predicted that black adult participants are more likely to report ideal selves corresponding to social change (e.g., political figures) (H2).

\subsubsection{Hypothesis testing}

Table 4 summarises the observed and expected frequency of ideal selves, confirming H1 and H2. The overall Pearson Chi-Square Test, $\chi^{2}(5)=46.72, p<.001$, was significant. The follow-up tests of multiple $2 \times 2$ relationships revealed that white participants reported significantly more often popular figures, $\chi^{2}(1)=32.92, p<.001$ (e.g., Princess Diana, Suzi Quatro, 
Madonna, Cher and Anni Lennox), whereas black participants reported significantly more often political figures, $\chi^{2}(1)=28.64$, $p<.001$ (e.g., Winnie and Nelson Mandela, Chris Hani, Steve Biko, Steve Tshwete and Allen Boesak).

\section{General discussion}

In three field studies conducted with adolescent and adult South Africans, we tested the general assumption that the preferences for certain types of ideal selves stand in a functional relationship to maintain or restore positive social identity and that the preferences for ideal selves, like social identity management strategies, are influenced by the shared beliefs about the relevant intergroup relations. The first two studies were conducted with white and black South African adolescents who perceived the status relations between black and white South Africans as secure, yet with different expectations. While black participants perceived the intergroup relations as secure in that social change to their advantage is guaranteed by the political power constellation, white participants perceived the intergroup relations as secure in that no change is assumed for the intergroup relations between black and white South Africans that could eliminate their perceived non-dominant status in comparison to black South Africans. In accordance with social identity theory we predicted that black participants in Studies 1 and 2 were likely to prefer ideal selves representing a prototype of the ingroup (social creativity); whereas white participants were expected to name ideal selves that either personify change in the individual's position (social mobility and individualisation), or personify a prototype of the ingroup (social creativity). The results of Study 1 and 2 supported our assumptions in that black participants reported significantly more often ideals representing a prototype of the ingroup while white participants, apart from listing ingroup prototypes as well, reported significantly more often ideal selves that allow them to shift from social to personal self-categorisation (individualisation).

We further reasoned that if our assumption that ideal selves stand in a functional relationship with social identity management strategies was to be correct it would be crucial to demonstrate the relationship between insecure status relations and ideal selves that promote social change. A third study was conducted with adult South Africans who were asked retrospectively about their ideal selves. The results showed that black adult participants, who were assumed to perceive the status relations between black and white South Africans as insecure when they were teenagers, reported significantly more often ideals personifying social change; whereas white adult participants who were assumed to perceive the status relations as secure while they were teenagers during apartheid reported significantly more often ideals representing a prototype of the ingroup (social creativity).

In the past, apartheid politics and legislation guaranteed white South Africans, which represent a minority group, dominance over almost all resources. The current social change process in South Africa, which is considered to be one of the most radical examples of social change (Habib \& Bentley, 2008) is similarly perceived by black and white participants, in that black South Africans as the majority are the beneficiaries of the social change (e.g., increasing political and economic power); whereas white South Africans, as the minority, are perceived as losing economic and political status. Given these shared beliefs about secure change of the intergroup relations, both groups' preferences for their ideal selves are also in line with a minority versus majority perspective. Black participants' preference for ideal selves prototypical for their ingroup might mirror their belief of representing the majority of South Africans, which determines values, norms and standards. White participants' preference for ideal selves corresponding to individualisation indicates that they might not only try to escape the negative evaluation of their ingroup due to apartheid but also come to terms with their minority status. The latter conclusion is informed by studies on minorities within immigrant contexts which demonstrated for instance that minorities value family much more than they value the broader community (e.g., Merz, Oort, Oezeke-Kocabas, \& Schuengel, 2009).

The rather small number of black participants naming ideal selves corresponding to individualisation might require a different explanation. One could argue that being prototypical rather than "unique" is functional for benefiting from becoming the dominant group economically and politically as it is perceived by black and white participants for black South Africans. The concept of prototypicality is central to self-categorisation theory (Turner et al., 1987) which proposes that even though only a limited number of ingroup members meet all the defining features of a category; the prototypical member is the reference according to which ingroup members judge and are judged. When we take the personified ideal selves most frequently named by black participants (and who they represent) into consideration one gets an idea about the "defining features of being a black South African", namely to be financially successful. For instance, Patrick Motsepe was named most frequently in Study 1 and 2 as somebody black participants wanted to be like. Patrick Motsepe typifies a success story in the new South Africa; namely to be South Africa's first black billionaire. The significance of financial success for black South Africans is understandable if one takes the discrepancy between subjective perceived economic intergroup differences (as assessed in this research) and the actual financial situation of the two groups into account. Although, the black (and white) participants perceive black South Africans economically as very close (Study 1) or even superior (Study 2) relative to white South Africans, the actual household income across these two populations tells a different story. According to the recently published census data, black South African households earn still six times less than white South African households (Statistics South Africa, 2012).

\subsection{Limitations}

As the present studies were based on a cross-sectional research design, the results do not allow for drawing any conclusion about the directedness of the functional relationship between ideal selves and identity management strategies which 
represents one of the major limitations (see Kessler \& Mummendey, 2002, for a detailed discussion of causality in social identity theory). A second limitation refers to the ideals assessed from adult participants (Study 3), because memory biases might have been at play. The alternative would have been to collect data from another society in which the intergroup relation is seen by the respective groups as more insecure. However, such a study would have been problematic as well, given that different groups with different cultural background would have been studied rendering results difficult to compare. Given this unavoidable trade-off, we opted for a retrospective study and further research might be able to triangulate these findings by using a different method. Finally, one important limitation results from the interferences of the perceptions of past and current intergroup relations as secure versus insecure using indirect rather than direct measures.

\subsection{Conclusion}

Despite these limitations, the results of the study contributed to extending our understanding of the relationship between ideal selves and the social context. Most importantly, we hope that the study demonstrated that social identity theory (Tajfel \& Turner, 1979, 1986) represents a useful theoretical framework to conceptualise social change but it also demonstrates its limitations. The latter became obvious when institutionalised social change had to be taken into account. Thus, while in principle providing the necessary conceptual tool for the understanding of the role of ideal selves in adolescents' social identity, social identity theory might have to be enlarged in its coverage of possible shared belief systems in intergroup relations. In the case of this study, it became obvious that peoples' predictions of future status change are necessary but not sufficient in order to assess their beliefs of secure and insecure intergroup relations. An important question is whether status change itself is seen as secure (e.g., guaranteed by powerful institutions) or insecure. Although our data do not allow for generalisations we would speculate that this question is not only relevant for South Africa but also for other societal contexts where radical social change is initiated but the implementation has not been concluded.

Lastly, the current research contributed to the over 100 year long tradition of studies on ideals (see Teigen et al., 2000) as well as to the more recent research based on the theory of possible selves. It also shows, however, that interpretations of individuals' ideal selves in relation to the social context are more plausible when a consistent and comprehensive theoretical framework is taken into account. In the current study social identity theory was chosen as theoretical framework for conceptual reasons. That does not exclude the possibility that alternative theoretical frameworks such as Social Dominance Theory (Sidanius \& Pratto, 1999) and System Justification Theory (Jost \& Banaji, 1994; Jost, Banaji, \& Nosek, 2004) might contribute to the extension of our understanding of the functional relationship between ideal and social change. Our social identity approach for the analysis of individuals' ideal selves provides a window that allows looking into otherwise probably less accessible social change processes on the level of social identities. Consequently, the study of ideal selves from a social identity perspective might open pathway for new research perspectives on possible social identities (Cinnirella, 1998) which, like ideal personal selves, guide people in their responses to societal trends and changes.

\section{Acknowledgements}

We would like to express our gratitude to Ms Lynette Luke, Mr Lucky Malgas, Ms Glynnis Martin and Mr Onke Mazibuko from the University of Fort Hare for their support in collecting and coding the data of the present research.

\section{References}

Blanz, M., Mummendey, A., Mielke, R., \& Klink, A. (1998). Responding to negative social identity: A taxonomy of identity management strategies. European Journal of Social Psychology, 28, 697-729.

Brewer, B. B., \& Gardner, W. (1996). Who is this "We"? Levels of collective identity and self representation. Journal of Personality and Social Psychology, 71(1), 83-93.

Campbell, C. (1995a). The social identity of township youth: An extension of Social Identity Theory (Part 1). South African Journal of Psychology, 25(3), $150-159$.

Campbell, C. (1995b). The social identity of township youth: An extension of Social Identity Theory (Part 2). South African Journal of Psychology, 25(3), $160-167$.

Carver, C. S., \& Scheier, M. F. (1998). On the self-regulation of behavior. New York, NY: Cambridge University Press.

Cinnirella, M. (1998). Exploring temporal aspects of social identity: The concept of possible social identities. European Journal of Social Identity, 28, 227-248.

Darrah, E. M. (1898). A study of children’s ideals. Popular Science Monthly, 58, 88-98. Retrieved from http://en.wikisource.org/wiki/Popular_Science Monthly/Volume_53/May_1898/A_Study_of_Children's_Ideals

de la Sablonniere, R., Taylor, D. M., Perozzo, C., \& Sadykova, N. (2009). Reconceptualizing relative deprivation in the context of dramatic social change: The challenge confronting the people of Kyrgyztan. European Journal of Social Psychology, 39, 325-345.

Dumont, K., \& van Lill, B. (2009). Dominant and non-dominant groups' responses to social change: The economic transformation process in South Africa. South African Journal of Psychology, 39(4), 432-447.

Ellemers, N. (2002). Social identity and relative deprivation. In I. Walker, \& H. J. Smith (Eds.), Relative deprivation: Specification, development and integration (pp. 239-264). Cambridge: Cambridge University Press.

Ellemers, N., \& Bos, A. E. R. (1998). Individual and group level responses to threat experienced by Dutch shopkeepers in East-Amsterdam. Journal of Applied Social Psychology, 28, 1987-2005.

Ellemers, N., Spears, R., \& Doosje, B. (1997). Sticking together or falling apart: Ingroup identification as a psychological determinant of group commitment. Journal of Personality and Social Psychology, 72, 617-626.

Ellemers, N., Van Knippenberg, A., De Vries, N., \& Wilke, H. (1988). Social identification and permeability of group boundaries. European Journal of Social Psychology, 18(6), 497-513.

Finchilescu, G., \& de la Rey, C. (1991). Understanding intra-group variations in prejudice - The role of perceived legitimacy and stability. South African Journal of Psychology, 21(4), 225-232. 
Habib, A., \& Bentley, K. (Eds.). (2008). Racial redress and citizenship in South Africa. Cape Town: HSRC Press.

Hannover, B., Birkner, N., \& Pöhlmann, C. (2006). Ideal selves and self-esteem in people with independent or interdependent self-construal. European Journal of Social Psychology, 36(1), 119-133.

Haslam, S. A. (2001). Psychology in organisations: The social identity approach. London: Sage.

Higgins, E. T. (1989). Self-discrepancy theory: What patterns of self-belief cause people to suffer? In L. Berkowitz (Ed.), Advances in experimental psychology (pp. 93-136). San Diego, CA: Academic Press.

Hooker, K., \& Kaus, C. R. (1994). Health-related possible selves in young and middle adulthood. Psychology and Aging, 9, 126-133.

Jost, J. T., \& Banaji, M. R. (1994). The role of stereotyping in system-justification and the production of false consciousness. British Journal of Social Psychology, 33, 1-27. http://dx.doi.org/10.1111/j. 2044-8309.1994.tb01008.x

Jost, J. T., Banaji, M. R., \& Nosek, B. A. (2004). A decade of system justification theory: Accumulated evidence of conscious and unconscious bolstering of the status quo. International Society of Political Psychology, 25(6), 881-919. http://dx.doi.org/10.1111/j. 1467-9221.2004.00402.x

Kessler, T., \& Mummendey, A. (2002). Sequential or parallel processes? A longitudinal field study concerning determinants of identity-management strategies. Journal of Personality and Social Psychology, 82(1), 75-88.

Markus, H. R., \& Nurius, P. (1986). Possible selves. American Psychologist, 41(9), 954-969.

Merz, E. M., Oort, F. J., Oezeke-Kocabas, E., \& Schuengel, C. (2009). Intergenerational family solidarity: Value differences between immigrant groups and generations. Journal of Family Psychology, 23(3), 291-300.

Mummendy, A., Kessler, T., Klink, A., \& Mielke, R. (1999). Strategies to cope with negative social identity: Predictions by social identity theory and relative deprivation theory. Journal of Personality and Social Psychology, 76, 229-245.

Mummendy, A., Klink, A., Mielke, R., Wenzel, M., \& Blanz, M. (1999). Socio-structural characteristics of intergroup relations and identity management strategies: Results from a field study in East Germany. European Journal of Social Psychology, 29, $256-285$.

Niens, U., Cairns, E., Finchilescu, G., Forster, D., \& Tredoux, C. (2003). Social identity theory and the authoritarian personality theory in South Africa. South African Journal of Psychology, 33(2), 109-117.

Oyserman, D., Bybee, D., \& Terry, K. (2006). Possible selves and academic outcomes: How and when possible selves impel action. Journal of Personality and Social Psychology, 91(1), 188-204.

Schnare, B., MacIntyre, P., \& Doucette, J. (2012). Possible selves as a source of motivation for musicians. Psychology of Music, 40(1), 94-111.

Sidanius, J., \& Pratto, F. (1999). Social dominance: An intergroup theory of social hierarchy and oppression. Cambridge: University Press.

Simon, B., Aufderheide, B., \& Kampmeier, C. (2001). The social psychology of minority-majority relations. In R. Brown, \& S. S. Gaertner (Eds.), Blackwell handbook of social psychology: Intergroup processes (4) (pp. 303-323). Oxford: Blackwell.

Simon, B., \& Oakes, P. (2006). Beyond dependence: An identity approach of social power and dominance. Human Relations, 59(1), 105-139.

Statistics South Africa. (2012). Census 2012 - Statistical release. Retrieved from http://www.statssa.gov.za/Publications/P03014/P030142011.pdf

Strauss, K., Griffin, M. A., \& Parker, S. K. (2012). Future work selves: How salient hoped-for identities motivate proactive career behaviors. Journal of Applied Psychology, 97(3), 580-598.

Tajfel, H. (1981). Human groups and social categories: Studies in social psychology. Cambridge, UK: Cambridge.

Tajfel, H., \& Turner, J. C. (1979). An integrative theory of intergroup conflict. In W. G. Austin, \& S. Worchel (Eds.), The social psychology of intergroup relations (pp. 33-47). Monterey, CA: Brooks/Cole.

Tajfel, H., \& Turner, J. C. (1986). The social identity theory of intergroup behaviour. In W. G. Austin, \& S. Worchel (Eds.), Psychology of intergroup relations (2nd ed., 4, pp. 7-24). Chicago: Nelson-Hall.

Teigen, K. H., Normann, H. E., Bjorkheim, J. O., \& Helland, S. (2000). Who would you most like to be like? Adolescents' ideals at the beginning and the end of the century. Scandinavian Journal of Educational Research, 44(1), 5-27.

Turner, J. C., Hogg, M. A., Oakes, P. J., Reicher, S. D., \& Wetherell, M. S. (1987). Rediscovering the social group: A self-categorization theory. Oxford and New York: Basil Blackwell.

Turner, J. C. (2005). Explaining the nature of power: A three-process theory. European Journal of Social Psychology, 35(1), 1-22. 